I (Rondom)
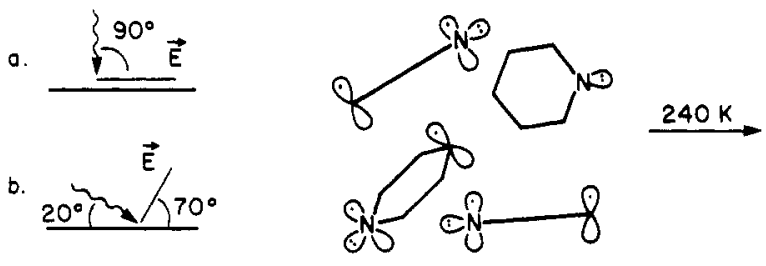

II (Tilled)

III (Perpendicular)

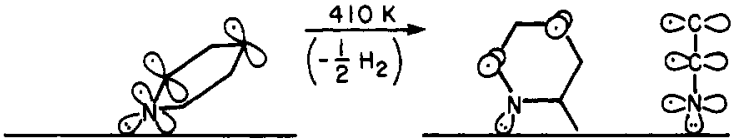

Figure 8. Proposed chemisorption states for pyridine on $\mathrm{Pt}(111)$. The diagrams on the left show the electric field direction that yield the NEXAFS spectra presented earlier. State I corresponds to Figure 4. State II corresponds to Figure 5 (assuming an unmixed state). State III corresponds to Figures 6 and 7.

is formed. Slowly at $240 \mathrm{~K}$ and more rapidly at higher temperatures the $\alpha \mathrm{C}-\mathrm{H}$ bond is cleaved and the pyridine is converted to an $\alpha$ pyridyl state characterized by the ring becoming perpendicular to the surface. This transformation may be reversible to an extent of approximately $10 \% .^{26}$
Acknowledgment. A. L. J. thanks Dr. David A. Shirley for helpful discussions and a critical reading of the manuscript. A.L.J. and E.L.M. (deceased) acknowlege the support of the National Science Foundation and the Chemical Sciences Division of the U. S. Department of Energy under Contract No. DE-AC0376SF00098. The work reported here was done at the Stanford Synchrotron Radiation Laboratory which is supported by the Office of Basic Energy Sciences of DOE and the Division of Materials Research of the National Science Foundation.

Registry No. Pt, 7440-06-4; pyridine, 110-86-1.

(26) It is interesting to note that for high coverages a pyridine desorption is evident at higher temperatures $(\sim 470 \mathrm{~K})$ and thus disproportionation of the pyridine might be invoked to provide for a small degree of reversibility of the formation of the $\alpha$ pyridyl. More detailed thermal desorption studies and EELS results will be presented by Grassian, V. and Muetterties, E. L. (in preparation).

(27) The gas-phase 1s binding energy relative to the vacuum level of carbon in pyridine is not known but should be between $290.2 \mathrm{eV}$ (C is for $\mathrm{C}_{6} \mathrm{H}_{6}{ }^{28 a}$ ) and $293.5 \mathrm{eV}$ ( $\mathrm{C}$ 1s for $\mathrm{HCN}^{28 b}$ ); the nitrogen 1s binding energy in pyridine is $404.9 \mathrm{eV}$. $^{28 \mathrm{c}}$ Resonances below the binding energy are bound-state resonances. For chemisorption states the onset of absorption corresponds to excitation to the Fermi level of the metal. Thus the region from the onset of absorption to the onset plus the work function are resonances below the photoemission threshold and correspond to the bound molecular resonances. The work function of pyridine covered $\mathrm{Pt}(111)$ for saturation coverage at 278 $\mathrm{K}$ is approximately $3 \mathrm{~V}^{13}$

(28) (a) Gelius, U.; Allan, C. J.; Johansson, G.; Siegbahn, H.; Allison, D. A.; Siegbahn, K. Phys. Scr. 1971, 3, 237. (b) Davis, D. W.; Hollander, J. M.; Shirley, D. A.; Thomas, T. D. J. Chem. Phys. 1970, 52, 3295. Thomas, T. D.; Shaw, Jr., R. W. J. Electron Spectrosc. Relat. Phenom. 1974, 5, 1081. (c) Brown, R. S.; Tse, A.; Vederas, J. C. J. Am. Chem. Soc. 1980, 102, 1174 Brown, R. S.; Tse, A. Can. J. Chem. 1980, 58, 694.

\title{
An Extended X-ray Absorption Fine Structure Study of Rhodium-Oxygen Bonds in a Highly Dispersed $\mathrm{Rh} / \mathrm{Al}_{2} \mathrm{O}_{3}$ Catalyst
}

\author{
D. C. Koningsberger, * J. B. A. D. van Zon, H. F. J. van't Blik, G. J. Visser, R. Prins, \\ Laboratory for Inorganic Chemistry and Catalysis, Eindhoven University of Technology, $5600 \mathrm{MB}$ Eindhoven, \\ The Netherlands
}

\author{
A. N. Mansour, D. E. Sayers, \\ Department of Physics, North Carolina State University, Raleigh, North Carolina 27650
}

\section{R. Short, ${ }^{\dagger}$ and J. R. Katzer ${ }^{\ddagger}$}

Center for Catalytic Science and Technology, Department of Chemical Engineering, University of Delaware, Newark, Delaware 97111 (Received: December 13, 1983)

\begin{abstract}
Analysis of in situ EXAFS measurements on a $2.4 \mathrm{wt} \% \mathrm{Rh} / \mathrm{Al}_{2} \mathrm{O}_{3}$ catalyst, reduced at $473 \mathrm{~K}$ after calcination at $623 \mathrm{~K}$, shows the presence of two different rhodium-oxygen bonds (viz. 2.05 and $2.68 \AA$ ). The oxygen neighbors of rhodium at a distance of $2.05 \AA$ disappear after reduction at $673 \mathrm{~K}$. The coordination distance $2.05 \AA$ is the same as found for $\mathrm{Rh}_{2} \mathrm{O}_{3}$ and indicates that this rhodium-oxygen bond is present due to incomplete reduction of the catalyst at $473 \mathrm{~K}$. Rhodium-oxygen bonds with a coordination distance of $2.68 \AA$ are present at both reduction temperatures. These bonds arise from a coordination of the interfacial rhodium atoms with the oxygen ions of the support. Assuming a half-spherical shape for the rhodium metal crystallites, numerical values for the average interfacial rhodium-oxygen coordination number $(N=2.5)$ and the crystallite diameter $(d=11 \AA)$ are derived from the experimental EXAFS parameters.
\end{abstract}

\section{Introduction}

The interaction between metal crystallites and the support can have a significant influence on the catalytic behavior of a supported catalyst. Several models have been proposed for the structure of

\footnotetext{
${ }^{\dagger}$ Current address: Engineering Technology Laboratory, Experimental Station, E.I. Dupont de Nemours and Co., Wilmington, DE 19898

${ }^{\ddagger}$ Current address: Central Research Department, Mobil Research and Development Corp., Princeton, NJ 08540.
}

the interface between the metal particle and the support. One model suggested that calcination of the catalyst before reduction is of importance to generate metal oxides which can interdiffuse with the oxidic support: $\mathrm{Ni} / \mathrm{SiO}_{2}, \mathrm{Ni} / \mathrm{Al}_{2} \mathrm{O}_{3}$, and $\mathrm{Co} / \mathrm{Al}_{2} \mathrm{O}_{3} .{ }^{1-4}$

(1) H. Suzuki, S. Takasaki, I. Koga, A. Meno, Y. Kotera, T. Sato, and N. Tode, Chem. Lett, 127 (1982).

(2) E. G. Derouane, A. J. Simoens, and J. C. Vedrine, Chem. Phys. Lett., 52, 549 (1977) 
Other authors have emphasized that the presence of metal ions in the interfacial region is functional in the metal-support interaction, with these metal ions serving as anchors for the metal crystallite: $\mathrm{Ru} / \mathrm{SiO}_{2}, \mathrm{Pt} / \mathrm{Al}_{2} \mathrm{O}_{3}$, and $\mathrm{Pt} / \mathrm{TiO}_{2}{ }^{5,6}$ Besson et al. ${ }^{7}$ proposed that $\mathrm{Os}_{3}(\mathrm{CO})_{12}$ clusters are bound to the silica support by means of an oxidative addition of supported hydroxyl groups to an Os-Os bond.

The extended X-ray absorption fine structure (EXAFS) technique has been used as a spectroscopic tool to gain information about the metal-support interface because of its sensitivity to short-range order. From EXAFS measurements on a $1 \mathrm{wt} \%$ $\mathrm{Ru} / \mathrm{SiO}_{2}$ catalyst, reduced at $673 \mathrm{~K}$, Lytle et al. ${ }^{8}$ attributed a peak in the magnitude of the Fourier transform to a $\mathrm{Ru}-\mathrm{O}$ bond with a distance larger than the distance known from $\mathrm{RuO}_{2}(2.03 \AA)$. They claimed that this oxygen belonged to the support. Lagarde et al. ${ }^{9}$ reported the presence of a $\mathrm{Pt}-\mathrm{O}$ bond (the coordination distance being equal to the $\mathrm{Pt}-\mathrm{O}$ distance in $\mathrm{PtO}_{2}$ ) in a 1 wt \% $\mathrm{Pt} / \mathrm{Al}_{2} \mathrm{O}_{3}$ catalyst, which was reduced in situ at $753 \mathrm{~K}$ after calcination. The $\mathrm{Pt}-\mathrm{O}$ bond was interpreted as arising from a metal-support interaction. Bassi et al. reported EXAFS measurements on a $0.2 \mathrm{wt} \% \mathrm{Au} / \mathrm{MgO}^{10}$ and a $3.5 \mathrm{wt} \% \mathrm{Au} / \mathrm{MgO}^{11}$ catalyst. Again, peaks in the magnitude of the Fourier transform were ascribed to $\mathrm{Au}-\mathrm{O}$ bonds, which originated from a goldsupport interaction.

Some questions have to be raised about the results mentioned above. The quality of some of the data is poor, and assignments were made only by comparing distances of peaks in the magnitude of the Fourier transform with those obtained from standard materials. In none of the above-mentioned cases was clear evidence given that these peaks originated from metal-oxygen bonds involved in a metal-support interaction.

Recently van Zon et al. ${ }^{12}$ showed that a metal-support oxygen distance could be detected using EXAFS measurements on a highly dispersed and well-reduced catalyst. They studied a catalyst prepared by direct reduction in a flow reactor at $773 \mathrm{~K}$ followed by passivation at room temperature. Before the EXAFS measurements were carried out, the catalyst was rereduced at $773 \mathrm{~K}$ in an in situ EXAFS cell. By separating the $\mathrm{Rh}-\mathrm{Rh}$ and $\mathrm{Rh}-$ support oxygen contributions from the data, they determined an $\mathrm{Rh}-\mathrm{O}$ distance of $2.71 \AA$.

In this paper results of EXAFS measurements on a highly dispersed $2.4 \mathrm{wt} \% \mathrm{Rh} / \mathrm{Al}_{2} \mathrm{O}_{3}$ catalyst will be reported. This catalyst has been calcined at $623 \mathrm{~K}$ so that initially all rhodium was present in the oxidic state. EXAFS spectra were then measured after in situ reduction at low $(473 \mathrm{~K})$ and high $(673$ $\mathrm{K}$ ) temperature. After reduction at $473 \mathrm{~K}$, two $\mathrm{Rh}-\mathrm{O}$ distances could be detected. One $\mathrm{Rh}-\mathrm{O}$ distance was equal to the distance known from $\mathrm{Rh}_{2} \mathrm{O}_{3}(2.05 \AA)$. Since this $\mathrm{Rh}-\mathrm{O}$ distance disappeared after reduction at $673 \mathrm{~K}$, it can be concluded that reduction at $473 \mathrm{~K}$ in the cell with preceding calcination at $623 \mathrm{~K}$ does not lead to a complete reduction of the catalyst. A $\mathrm{Rh}-\mathrm{O}$ distance of $2.68 \AA$ is present at both temperatures. Based upon the results of van Zon et al., ${ }^{12}$ this distance is assigned to a coordination of the interfacial rhodium atoms with the oxygen ions of the support. These results demonstrate that metal-support bonds can be analyzed in EXAFS data having a high signal-to-noise ratio but that

(3) R. B. Shalvoy, B. H. Davis, and P. J. Rencroft, Surf. Interface Anal., 2, $11(1980)$.

(4) R. B. Greegor, F. W. Lytle, R. L. Chin, and D. M. Hercules, J. Phys. Chem., 85, 1232 (1981).

(5) A. Bossi, F. Garbassi, G. Petrini, and L. Zanderighi, J. Chem. Soc., Faraday Trans. $1,78,1029$ (1982).

(6) T. Huizinga and R. Prins, J. Phys. Chem., 87, 173 (1983).

(7) B. Besson, B. Moraweck, A. K. Smith, J. M. Basset, R. Psaro, A. Fusi, and R. Ugo, J. Chem. Soc., Chem. Commun., 569 (1980).

(8) F. W. Lytle, G. H. Via, and J. H. Sinfelt, J. Chem. Phys. 67, 3831 (1977)

(9) P. Lagarde T. Murata, G. Vlaic, H. Dexpert, E. Freund, and J. P. Bourenonville, in "EXAFS and Near Edge Structure", A. Bianconi, L. Incoccia, and S. Stipich, Eds., Springer-Verlag, West Berlin, 1983.

(10) I. W. Bassi, F. W. Lytle, and G. Paravano, J. Catal., 42, 139 (1976).

(11) I. W. Bassi, F. Garbassi, G. Vlaic, A. Marzi, G. R. Tauszik, G. Coco, S. Galvagno, and G. Paravano, J. Catal., 64, 405 (1980).

(12) J. B. A. D. van Zon, D. C. Koningsberger, D. E. Sayers, H. F. J. van't Blik, and R. Prins, J. Chem. Phys., 80, 3914 (1984).
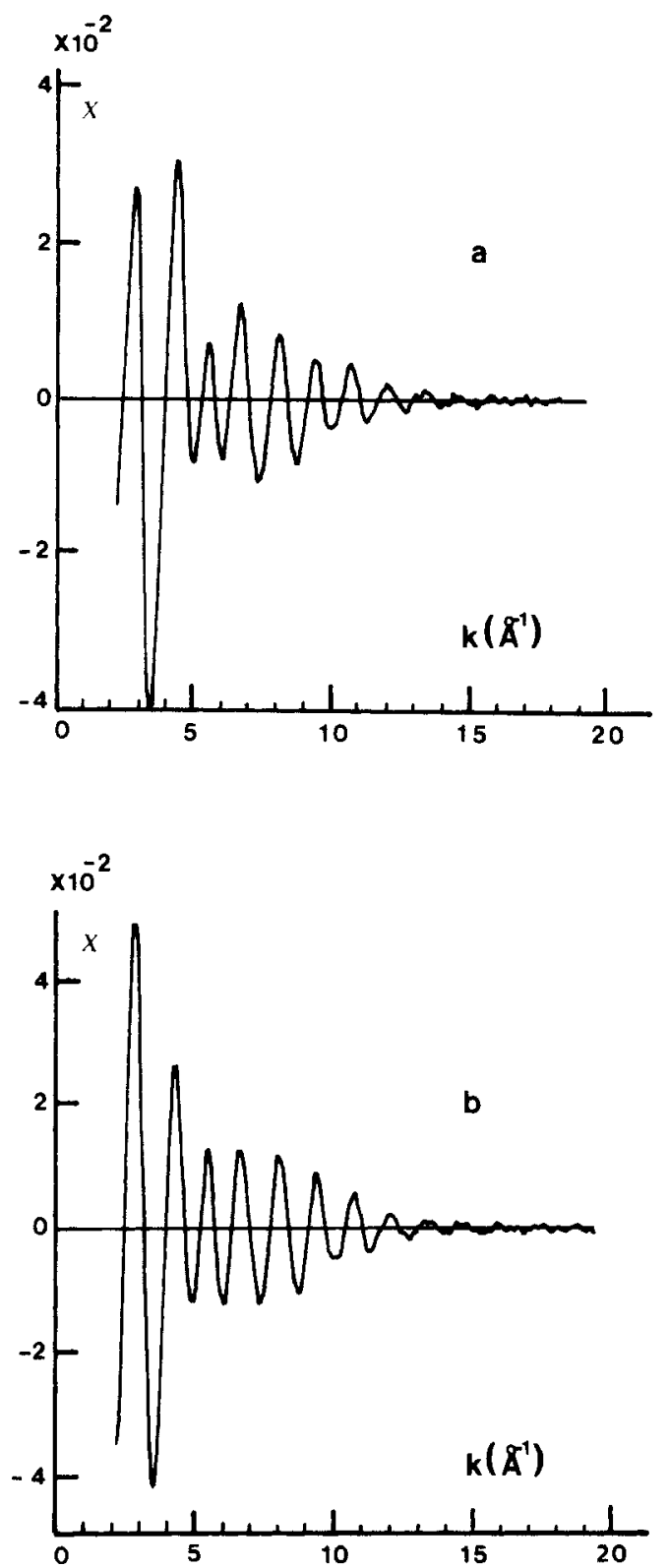

Figure 1. Raw EXAFS spectra of the $2.4 \mathrm{wt} \% \mathrm{Rh} / \mathrm{Al}_{2} \mathrm{O}_{3}$ catalyst: (a) $T_{\text {red }}=473 \mathrm{~K}$; (b) $T_{\text {red }}=673 \mathrm{~K}$.

care must be taken in the preparation of the catalyst and analysis of the data in order to separate the metal-support effects from those due to incomplete reduction.

\section{Experimental Section}

The $2.4 \mathrm{wt} \% \mathrm{Rh} / \mathrm{Al}_{2} \mathrm{O}_{3}$ catalyst was prepared by ion exchange on a $\gamma-\mathrm{Al}_{2} \mathrm{O}_{3}$ support with a solution of sulfate-free $\mathrm{Rh}\left(\mathrm{NO}_{3}\right)_{3}$. The support $\gamma-\mathrm{Al}_{2} \mathrm{O}_{3}$ (BET area of $194 \mathrm{~m}^{2} \cdot \mathrm{g}^{-1}$ ) was obtained by heating boehmite (Conoco Catapal) at $723 \mathrm{~K}$. The catalyst was dried in air at $383 \mathrm{~K}$ overnight to remove the adsorbed water and then calcined in flowing $\mathrm{O}_{2}$ at $623 \mathrm{~K}$ for $2 \mathrm{~h}$, after which it was stored for further use. Atomic absorption spectroscopy was used to determine the metal loading.

Hydrogen chemisorption was measured at room temperature after reduction at $473 \mathrm{~K}$ for $4 \mathrm{~h}$, followed by outgassing at 473 $\mathrm{K}$ for 2-4 h. The sample was cooled under vacuum to room temperature, and hydrogen chemisorption was measured. The total absorption isotherm yields a dispersion of 1.2 , assuming a $\mathrm{H} / \mathrm{Rh}$ stoichiometry of $1 . \mathrm{H} / \mathrm{Rh}$ values higher than 1 on $\mathrm{Rh} /$ $\mathrm{Al}_{2} \mathrm{O}_{3}$ catalysts have been observed previously ${ }^{13,14}$ and are explained by multiple adsorption.

(13) S. E. Wanke and N. A. Dougharty, J. Catal., 24, 367 (1972).

(14) H. C. Yao, S. Japar, and M. Shelef, J. Catal., 50, 407 (1977). 

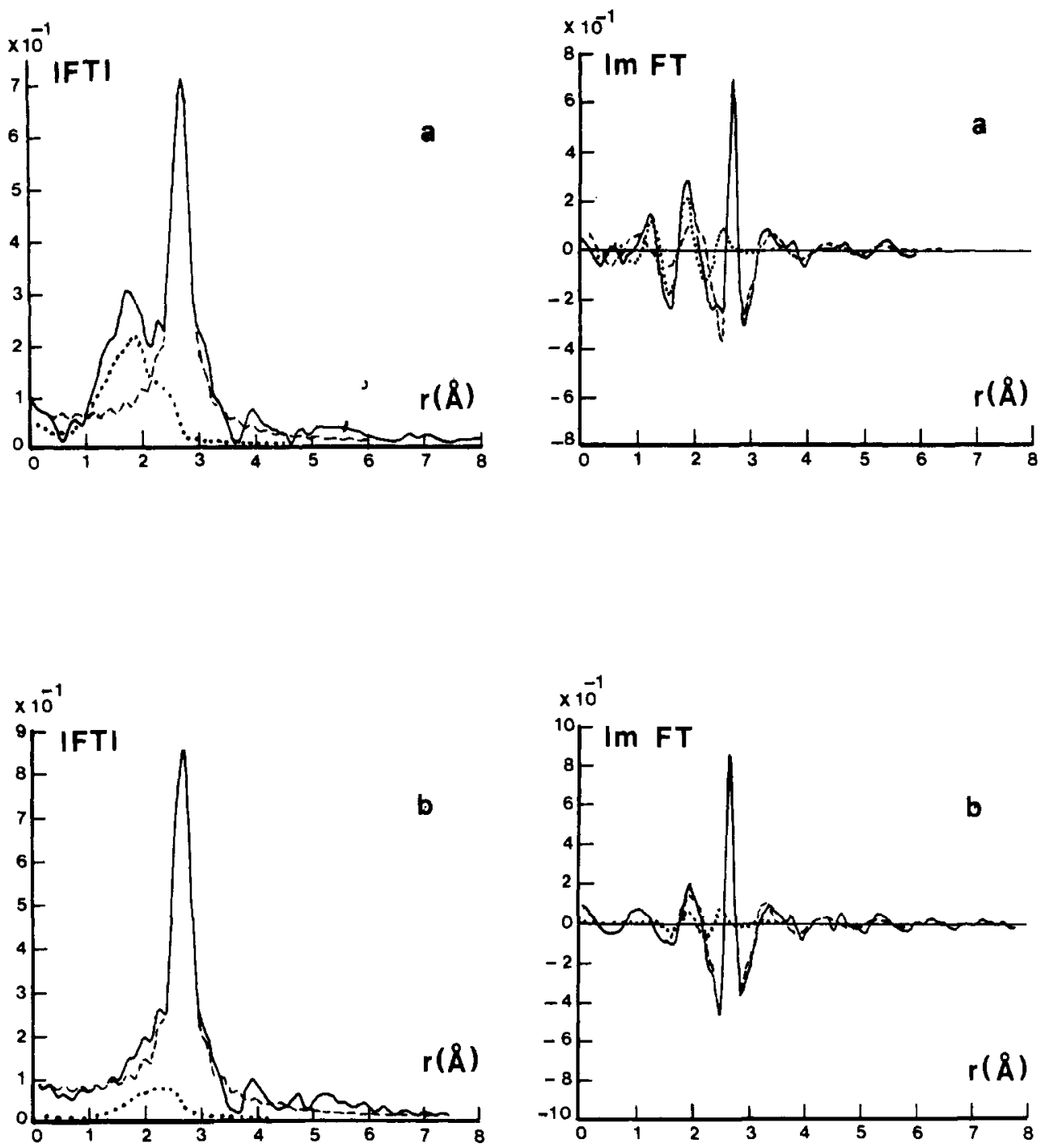

Figure 2. Fourier transform ( $k^{1}$ weighed, Rh-Rh phase and amplitude corrected, $k_{\min }=3.3 \AA^{-1}, k_{\max }=14.5 \AA^{-1}$ ) of experimental EXAFS data ( - ) and calculated $\mathrm{Rh}-\mathrm{Rh}(-\ldots)$ and $\mathrm{Rh}-\mathrm{O}$ EXAFS $(\cdots)$ (for parameters see Table I): (a) $T_{\text {red }}=473 \mathrm{~K}$; (b) $T_{\text {red }}=673 \mathrm{~K}$.

The dried catalyst was pressed into a thin self-supporting wafer and mounted in the in situ EXAFS cell.15 The thickness of the wafer was chosen to give $\Delta \mu x \sim 1.5$ at the rhodium edge. Reduction was carried out under flowing $\mathrm{H}_{2}$ for $2 \mathrm{~h}$ at $473 \mathrm{~K}$, with the temperature being increased at a heating rate of $2.5 \mathrm{~K} / \mathrm{min}$. The sample was then cooled to room temperature under flowing $\mathrm{H}_{2}$, and EXAFS spectra were recorded at $90 \mathrm{~K}$ with the catalyst exposed to $1 \mathrm{~atm}$ of static hydrogen. The same procedure was used for the subsequent reduction at $673 \mathrm{~K}$.

The EXAFS spectra of the rhodium $K$ edge were recorded in situ on X-ray beam line I-5 at the Stanford Synchrotron Radiation Laboratory (SSRL) with a ring energy of $3 \mathrm{GeV}$ and ring currents between 40 and $80 \mathrm{~mA}$.

\section{Data Analysis and Results}

EXAFS oscillations in $k$ space are obtained from the X-ray absorption spectrum by a cubic spline background subtraction startig at $20 \mathrm{eV}$ above the edge. ${ }^{16}$ The EXAFS oscillations are normalized by division by the height of the edge. Reference compounds are used to obtain phase and backscattering amplitude functions and are treated in the same way. Parts a and b of Figure 1 present the EXAFS oscillations in $k$ space of the $2.4 \mathrm{wt} \%$ $\mathrm{Rh} / \mathrm{Al}_{2} \mathrm{O}_{3}$ catalyst reduced at 473 and $673 \mathrm{~K}$, respectively.

It has been shown ${ }^{12}$ that Fourier transformation ( $k^{1}$ weighed) of the EXAFS data obtained from a highly dispersed $\mathrm{Rh} / \mathrm{Al}_{2} \mathrm{O}_{3}$ catalyst produces a strong side lobe in the $\mathrm{R}$ region, where con-

(15) S. A. Kent, Thesis, University of Delaware, Newark, DE, 1975.

(16) J. W. Cook Jr. and D. E. Sayers, J. Appl. Phys., 52, 5024 (1981). tributions of oxygen can be expected. However, this side lobe also has contributions due to nonlinearities in the rhodium phase shift and due to the $k$ dependence of the rhodium backscattering amplitude. These effects can be decreased by raising the power $n$ of the weight factor $k^{n}$ in the Fourier transformation. However, when higher $n$ values are used, the Fourier transform becomes less sensitive to contributions from oxygen, since low- $Z$ elements (like oxygen) have most scattering power at low $k$ values. When the phase shift and the backscattering amplitude are removed from the EXAFS function before a transformation is done, the Fourier transform simplifies to a transform of a sinelike function. ${ }^{17}$ In a Fourier transform which is corrected for the rhodium phase shift function and backscattering amplitude (further indicated by FT'), a $R h-R h$ coordination peak will show up as a single symmetrical peak localized at the actual coordination distance. Reliable data for phase and backscattering amplitude have been obtained from EXAFS measurements on rhodium foil. ${ }^{18}$ The solid lines in Figure $2 \mathrm{a}, \mathrm{b}$ show the $k^{1}$-weighed $\mathrm{FT}^{\prime}$ for both reduction temperatures. Clearly visible are extra contributions in the $R$ region between 1 and $2.2 \AA$. Before Fourier transformation the raw EXAFS data were smoothed by removing noise (harmonic numbers higher than 200) via Fourier filtering.

Fitting in $k$ space is a widely used technique to determine the EXAFS parameter values. However, this method is not reliable enough to determine the smaller oscillations from other atoms

(17) P. A. Lee and G. Beni, Phys. Rev. B: Solid State, 15, 2862 (1977).

(18) J. B. A. D. van Zon, D. C. Koningsberger, H. F. J. van't Blik, and D. E. Sayers, $J$. Chem. Phys., 82, 5742 (1985). 

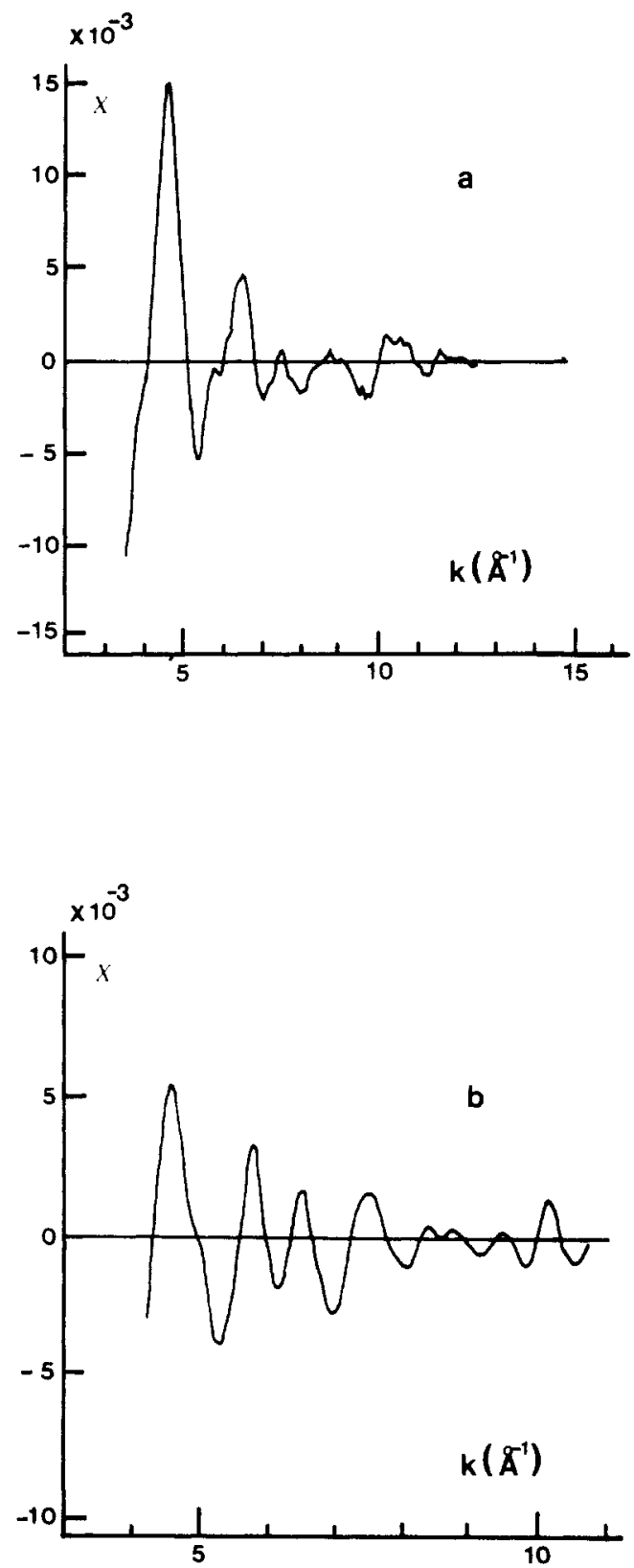

Figure 3. Residual spectra obtained after subtraction of the calculated $\mathrm{Rh}-\mathrm{Rh}$ contribution from the experimental data: (a) $T_{\text {red }}=473 \mathrm{~K}$; (b) $T_{\text {red }}=673 \mathrm{~K}$.

(e.g. support oxygen), whose frequencies are close to the frequency of the main peak. However, by use of the phase- and amplitude-corrected Fourier transorm described above, the $\mathrm{Rh}-\mathrm{Rh}$ contribution may be more localized and separated from other contributions. The data analysis has been started with the catalyst reduced at $673 \mathrm{~K}$ because of its less complex structure compared with the catalyst reduced at $473 \mathrm{~K}$. By means of first guess parameters, obtained by a $\log$ ratio plot, a $\mathrm{Rh}-\mathrm{Rh}$ EXAFS function is calculated (using the experimental $R h-R h$ phase and amplitude, obtained from the rhodium foil) and subtracted from the experimental data. As a check on the $\mathrm{Rh}-\mathrm{Rh}$ start parameters, the residual spectrum is transformed ( $\mathrm{Rh}-\mathrm{Rh}$ phase and amplitude corrected). The initial parameters have to be adjusted if significant $\mathrm{Rh}-\mathrm{Rh}$ oscillations are present in the imaginary part of this transform. We have found that the final $R h-R h$ parameters, obtained in this way, are not too much different from the initial parameter values. However, these small differences in $R h-R h$ parameters can lead to significant $R h-R h$ oscillations in the residual spectrum, which make the proper analysis of this spectrum difficult. After a correct choice of the $R h-R h$ parameters and with a sufficiently high signal-to-noise ratio of the original data, the residual spectrum (see Figure $3 \mathrm{~b}$ ) can now reveal the identity
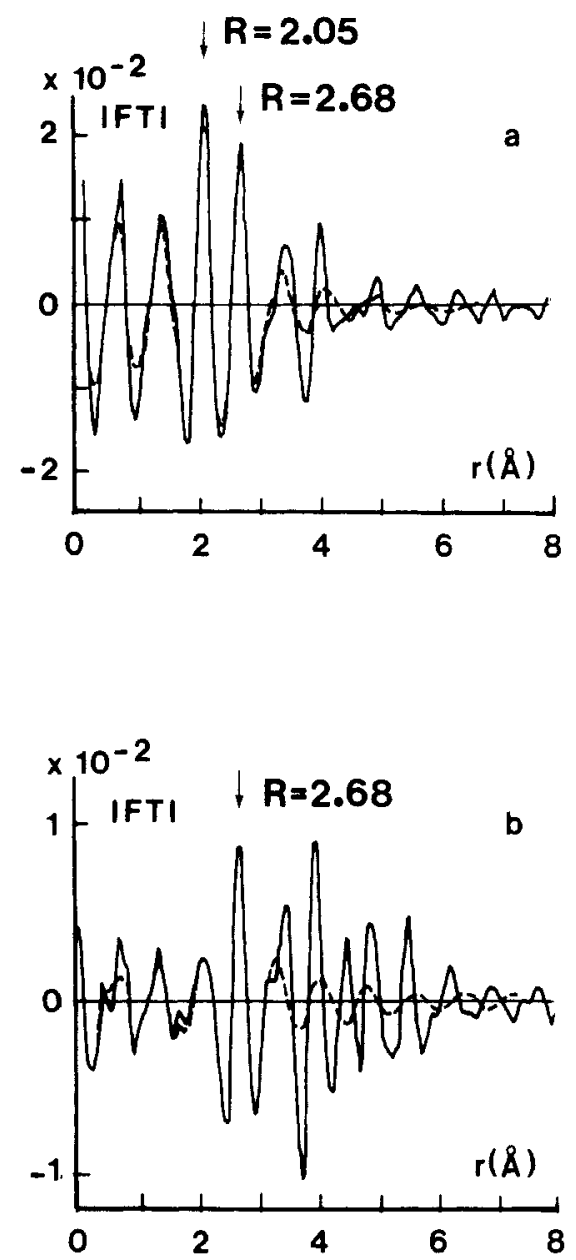

Figure 4. Imaginary part of the Fourier transform ( $k^{l}$ weighed, $\mathrm{Rh}-\mathrm{O}$ phase corrected, $k_{\min }=4 \AA^{-1}, k_{\max }=10 \AA^{-1}$ ) of the difference spectrum (solid line) and calculated $\mathrm{Rh}-\mathrm{O}$ EXAFS (dotted line) (for parameters see Table I: (a) $T_{\text {red }}=473 \mathrm{~K}$; (b) $T_{\text {red }}=673 \mathrm{~K}$.

of the scatterer(s), causing the differences between $R=1$ and $3 \AA$. Since the catalyst has been prepared from $\mathrm{Rh}\left(\mathrm{NO}_{3}\right)_{3}$, the only possible scatterer for the reduced catalyst can be oxygen. A Fourier transform (corrected for $\mathrm{Rh}-\mathrm{O}$ phase shift, obtained from EXAFS measurements on $\mathrm{Rh}_{2} \mathrm{O}_{3}{ }^{18}$ performed on the residual spectrum shows that the imaginary part of this transform is symmetric for $2<R<3 \AA$ (see Figure $4 \mathrm{~b}$, solid line) and peaks at $2.68 \AA$ in the maximum of its magnitude. This confirms the presence of oxygen as scatterer at a coordination distance of 2.68 $\AA$. This is further verified by back-transformation to $k$ space of the peak at $2.68 \AA$ (see Figure $5 \mathrm{~b}$, solid line). Fitting in $k$ space (using phase shift and backscattering amplitude of $\mathrm{Rh}_{2} \mathrm{O}_{3}$ ) results in parameter values for a single $\mathrm{Rh}-\mathrm{O}$ bond. Peaks due to higher $\mathrm{Rh}-\mathrm{Rh}$ coordination shells are also visible in Figure $4 \mathrm{~b}$. These peaks will not be analyzed in this paper. As a final check on both sets of parameters ( $\mathrm{Rh}-\mathrm{Rh}$ and $\mathrm{Rh}-\mathrm{O}$ ), an EXAFS function calculated with the obtained $\mathrm{Rh}-\mathrm{O}$ parameters is subtracted from the experimental data, resulting in a spectrum which should contain only the frequency of rhodium scatterers. A Rh- Rh phaseand amplitude-corrected Fourier transform on this spectrum should therefore result in a symmetric imaginary part which peaks positively in the maximum of the magnitude. If necessary, better $\mathrm{Rh}-\mathrm{Rh}$ parameters can be obtained from back-transformation of this transform to restart the whole procedure. In this recurring way the $\mathrm{Rh}-\mathrm{Rh}$ and $\mathrm{Rh}-\mathrm{O}$ parameters have been determined as given in Table $\mathrm{I}$.

The same procedure has been applied to the EXAFS data of the $\mathrm{Rh} / \mathrm{Al}_{2} \mathrm{O}_{3}$ sample, reduced at $473 \mathrm{~K}$. Two distinct peaks can be observed (Figure 4a) in the Fourier transform of the difference spectrum for $1<R<3 \AA$. Back-transformation of this transform gives an EXAFS signal, which can be fitted with two different $\mathrm{Rh}-\mathrm{O}$ coordinations (see Figure $5 \mathrm{a}$ and parameters Table I). The 

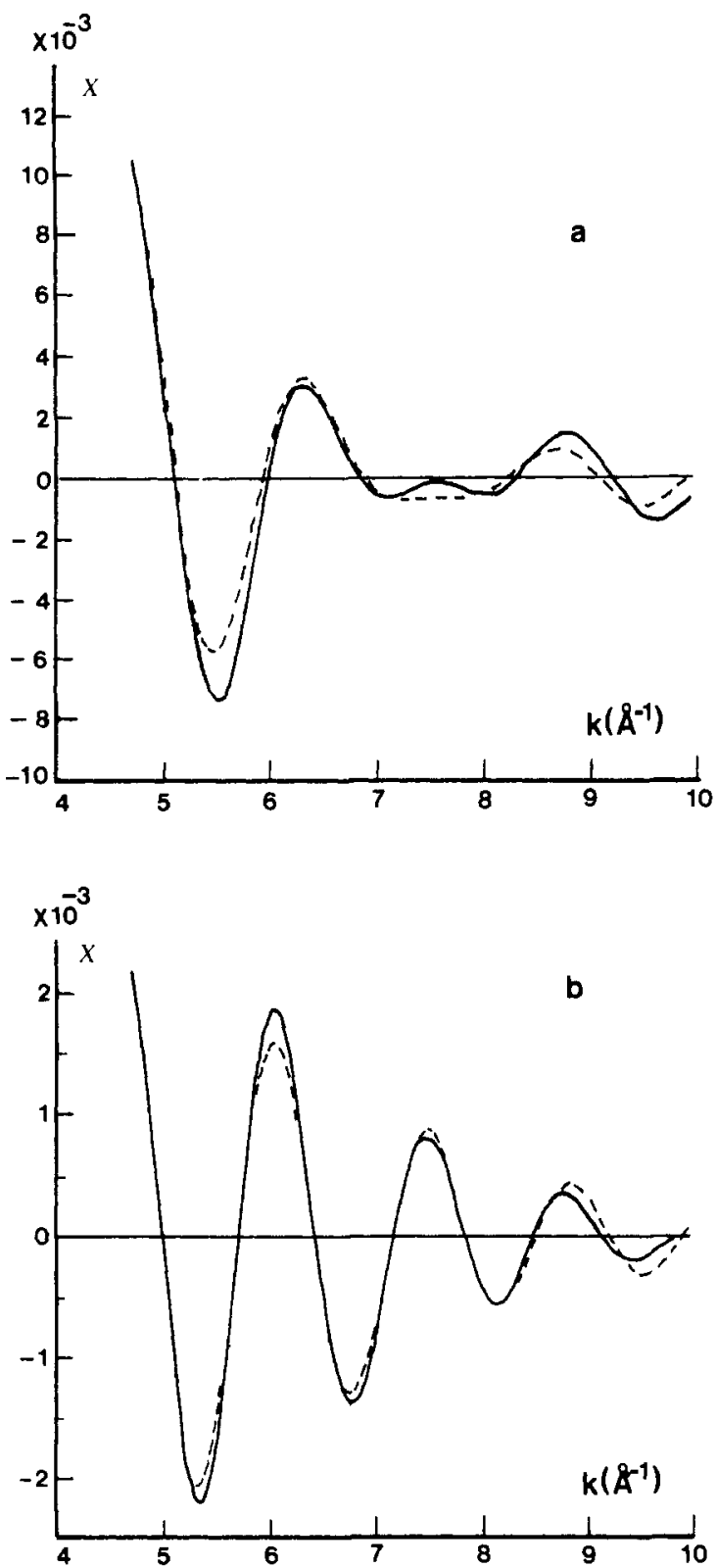

Figure 5. EXAFS obtained by back-transformation of Figure 3 (solid line) and calculated Rh-O EXAFS (dotted line) (for parameters see Table I): (a) $T_{\text {red }}=473 \mathrm{~K}\left(R_{\min }=1.2 \AA, R_{\max }=3.2 \AA\right)$; (b) $T_{\text {red }}=673$ $\mathrm{K}\left(\mathrm{R}_{\min }=1.9 \AA, R_{\max }=3.2 \AA\right)$.

TABLE I: Coordination Parameters ${ }^{a}$

\begin{tabular}{ccccc}
\hline & & \multicolumn{3}{c}{$\mathrm{Rh}(2.4) / \mathrm{Al}_{2} \mathrm{O}_{3}$} \\
\cline { 3 - 5 } treatment & coordination & $N$ & \multicolumn{1}{c}{$R, \AA$} & $10^{-3} \Delta \sigma^{2}, \AA^{2}$ \\
\hline reduction at 473 K & $\mathrm{Rh}^{0}-\mathrm{Rh}^{0}$ & 5.2 & 2.69 & 5.5 \\
& $\mathrm{Rh}^{3+}-\mathrm{O}^{2-}$ & 1 & 2.05 & 0 \\
& $\mathrm{Rh}^{0}-\mathrm{O}_{\mathrm{s}}{ }^{2-}$ & 1.3 & 2.68 & 0 \\
reduction at 673 K & $\mathrm{Rh}^{0}-\mathrm{Rh}^{0}$ & 6.3 & 2.69 & 5.3 \\
& $\mathrm{Rh}^{0}-\mathrm{O}_{\mathrm{s}}{ }^{2-}$ & 1.2 & 2.68 & 0
\end{tabular}

${ }^{a} N=$ number of neighbors, $R=$ distance, $\Delta \sigma^{2}=$ Debije-Waller factor, difference with reference compound. Accuracies: $N \pm 10-20 \%$, $R \pm 0.5-1 \%, \Delta \sigma^{2} \pm 10-20 \%$

reliability of the $\mathrm{Rh}-\mathrm{O}$ parameters obtained for both reduction temperatures has been checked by comparing the Fourier transforms of the difference spectra with the transforms of the $\mathrm{Rh}-\mathrm{O}$ EXAFS functions calculated with the parameters given in Table I. It can be seen in Figure 4 that within the $R$ region used for back-transformation to $k$ space both transforms are very similar.

The Fourier transforms of the calculated $\mathrm{Rh}-\mathrm{O}$ coordination(s) can now be compared in Figure 2 with the transforms of the corresponding calculated $\mathrm{Rh}-\mathrm{Rh}$ coordination and those of the experimental data. As a final check for the reliability of the $\mathrm{Rh}-\mathrm{Rh}$ and $\mathrm{Rh}-\mathrm{O}$ parameters derived in this work, the EXAFS functions of both coordinations have been added and transformed. The equivalence of these transforms with those of the corresponding experimental data can be seen in Figure 6 . It is also shown that the calculated $\mathrm{Rh}-\mathrm{Rh}+\mathrm{Rh}-\mathrm{O}$ EXAFS functions are identical with the EXAFS functions obtained by back-transformation $\left(R_{\min }=0.8 \AA, R_{\max }=3.2 \AA\right)$ of the Fourier transform of the corresponding experimental data.

\section{Discussion}

The analysis of the EXAFS data obtained on the $2.4 \mathrm{wt} \%$ $\mathrm{Rh} / \mathrm{Al}_{2} \mathrm{O}_{3}$ catalyst gives evidence for the presence of two types of $\mathrm{Rh}-\mathrm{O}$ bonds. One $\mathrm{Rh}-\mathrm{O}$ bond has a coordination distance of $2.05 \AA$ which is equal to the distance found in $\mathrm{Rh}_{2} \mathrm{O}_{3}$. This $\mathrm{Rh}-\mathrm{O}$ bond disappears after reduction at $673 \mathrm{~K}$. Therefore, we conclude that this bond originates from $\mathrm{Rh}_{2} \mathrm{O}_{3}$ species which are still present after the reduction at $473 \mathrm{~K}$. The second $\mathrm{Rh}-\mathrm{O}$ bond, with a coordination distance of $2.68 \AA$ detected at both reduction temperatures, is similar to the bonds measured for a 0.5 and $1.0 \mathrm{wt}$ $\% \mathrm{Rh} / \mathrm{Al}_{2} \mathrm{O}_{3}$ catalyst $(R=2.71 \AA)$ reported previously. ${ }^{12,18}$ This $\mathrm{Rh}-\mathrm{O}$ bond has been assigned to a coordination of the interfacial rhodium metal atoms with support oxygen ions. However, in contrast to the calcination and reduction procedure employed for the $2.4 \mathrm{wt} \%$ catalyst, the 0.5 and $1.0 \mathrm{wt} \% \mathrm{Rh} / \mathrm{Al}_{2} \mathrm{O}_{3}$ catalysts were directly reduced at $773 \mathrm{~K}$ without a preceding calcination step. Thus, even a preceding calcination at $623 \mathrm{~K}$ of the $\mathrm{Rh}-$ (2.4) $/ \mathrm{Al}_{2} \mathrm{O}_{3}$ catalyst, followed by a complete reduction, does not lead to the presence of normal cation-anion distances, which have been supposed in the literature $e^{8-11}$ to be representative for an interaction between metal crystallites and support. From the results reported earlier ${ }^{12,18}$ and from results obtained in this work, one has to conclude that in $\mathrm{Rh} / \mathrm{Al}_{2} \mathrm{O}_{3}$ catalysts the structure of the metal-support interface consists of bonds between rhodium atoms and oxygen ions of the support with a bond length of about $2.7 \AA$. This means that the rhodium metal crystallites are not bound to the support via a rhodium oxide layer with Coulombic rhodium-cation oxygen-anion interactions. It has been suggested by van Zon et al. ${ }^{12}$ that this interaction is possibly via an ioninduced dipole interaction.

The fraction of rhodium still present in the rhodium oxide phase after reduction at $473 \mathrm{~K}$ can be calculated by assuming that partially reduced rhodium metal crystallites are not present. This is a reasonable assumption since it is generally accepted that the nucleation phase of the reduction of small metal oxide particles is rate determining. Thus, once the reduction process starts, the small crystallite is completely reduced. It is also known ${ }^{19}$ that highly dispersed $\mathrm{Rh} / \mathrm{Al}_{2} \mathrm{O}_{3}$ catalysts are neither monatomically dispersed nor have a form of dispersion consisting of a mixture of rhodium metal crystallites and isolated $\mathrm{Rh}^{0}$ atoms. Thus, it follows that after reduction at $473 \mathrm{~K}$ rhodium is present only in oxidic or in metallic particles. Both the $\mathrm{Rh}^{0}$ atoms and the $\mathrm{Rh}^{3+}$ ions contribute to the edge jump and thus influence the normalization. This implies that the real coordination numbers $\left(N_{\mathrm{r}}\left(\mathrm{Rh}^{0}-\mathrm{Rh}^{0}\right)\right.$ and $\left.N_{\mathrm{r}}\left(\mathrm{Rh}^{3+}-\mathrm{O}^{2-}\right)\right)$ are related to the measured coordination numbers $\left(N_{\mathrm{m}}\left(\mathrm{Rh}^{0}-\mathrm{Rh}^{0}\right)\right.$ and $\left.N_{\mathrm{m}}\left(\mathrm{Rh}^{3+}-\mathrm{O}^{2-}\right)\right)$ by

$$
\begin{gathered}
N_{\mathrm{r}}\left(\mathrm{Rh}^{0}-\mathrm{Rh}^{0}\right)=N_{\mathrm{m}}\left(\mathrm{Rh}^{0}-\mathrm{Rh}^{0}\right) /(1-f) \\
N_{\mathrm{r}}\left(\mathrm{Rh}^{3+}-\mathrm{O}^{2-}\right)=N_{\mathrm{m}}\left(\mathrm{Rh}^{3+}-\mathrm{O}^{2-}\right) / f
\end{gathered}
$$

with $f$ being the fraction of rhodium present in the $\mathrm{Rh}_{2} \mathrm{O}_{3}$. Since the crystallographic coordination number $N_{\mathrm{r}}\left(\mathrm{Rh}^{3+}-\mathrm{O}^{2-}\right)$ in rhodium(III) oxide equals 6 and the measured coordination number $N_{\mathrm{m}}\left(\mathrm{Rh}^{3+}-\mathrm{O}^{2-}\right)=1$ (cf. Table I), it follows by eq 2 that, after reduction at $473 \mathrm{~K}, 17 \%$ of the rhodium atoms are still present in the rhodium oxide phase. Given the fact that $f=0.17$ and $N_{\mathrm{m}}\left(\mathrm{Rh}^{0}-\mathrm{Rh}^{0}\right)=5.2$, the real rhodium coordination number $N_{\mathrm{r}}\left(\mathrm{Rh}^{0}-\mathrm{Rh}^{0}\right.$ ) (after reduction at $473 \mathrm{~K}$ ) is calculated to be 6.3

(19) H. F. J. van't Blik, J. B. A. D. van Zon, T. Hujzinga, J. C. Vis, D. C. Koningsberger, and R. Prins, J. Phys. Chem, 87, 2264 (1983) 

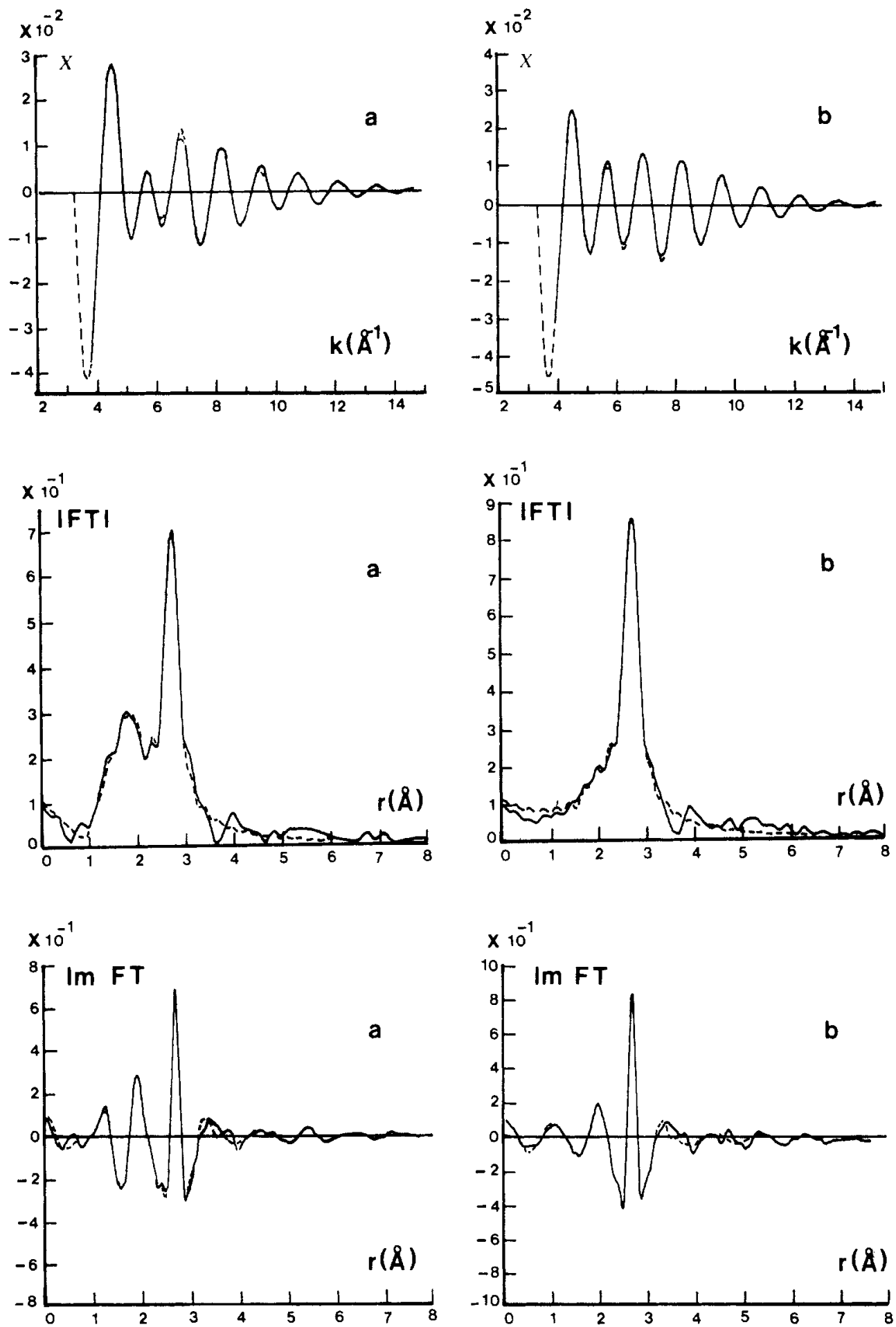

Figure 6. EXAFS obtained by back-transformation $\left(R_{\min }=0.8 \AA, R_{\max }=3.2 \AA\right)$ of Figure 2 (solid lines) and calculated EXAFS (Rh-Rh $+\mathrm{Rh}-\mathrm{O}$ ) (dotted line). Fourier transformation ( $k^{1}$ weighed, $\mathrm{Rh}-\mathrm{Rh}$ phase and amplitude corrected, $\left.k_{\min }=3.3 \AA^{-1}, k_{\max }=14.5 \AA^{-1}\right)$ of experimental EXAFS data (solid line) and calculated EXAFS ( $\mathrm{Rh}-\mathrm{Rh}+\mathrm{Rh}-\mathrm{O}$ ) (dotted line): (a) $T_{\text {red }}=473 \mathrm{~K}$; (b) $T_{\text {red }}=673 \mathrm{~K}$.

(eq 1). This value can be compared with the real rhodiumrhodium coordination number found after reduction at $673 \mathrm{~K}$. In this case only one type of rhodium atom is present, implying that $N_{\mathrm{r}}\left(\mathrm{Rh}^{0}-\mathrm{Rh}^{0}\right)=N_{\mathrm{m}}\left(\mathrm{Rh}^{0}-\mathrm{Rh}^{0}\right)=6.3$. This number is equal to the value obtained after reduction of the catalyst at $473 \mathrm{~K}$. This shows that the reduction at $673 \mathrm{~K}$ has not led to a noticeable sintering of the metal crystallites. This also indicates that the presence of partially reduced metal crystallites with a metal oxide layer between the metal particle and the support is very unlikely, since a further reduction of these particles at higher temperatures should give an increase of the coordination number.

The number of support oxygen ions which are in contact with one interfacial rhodium atom can be estimated as follows. The ratio between the number of interfacial metal atoms, $N_{\text {int }}$, in a particle with (assumed) half-spherical shape and the total number of atoms, $N_{\mathrm{t}}$, present in this particle is given by ${ }^{18}$

$$
N_{\text {int }} / N_{\mathrm{t}}=4 R_{\text {at }} / d
$$

with $d$ the diameter of the particle and $R_{\mathrm{at}}$ the atomic radius of the rhodium atom. The relationship between the real $N_{\mathrm{r}}\left(\mathrm{Rh}^{0} \mathrm{O}_{\mathrm{s}}{ }^{2-}\right)$ and the measured $N_{\mathrm{m}}\left(\mathrm{Rh}^{0}-\mathrm{O}_{\mathrm{s}}{ }^{2-}\right)$ coordination number of the rhodium support-oxygen bond can now be derived:

$$
N_{\mathrm{r}}\left(\mathrm{Rh}^{0}-\mathrm{O}_{\mathrm{s}}{ }^{2-}\right)=N_{\mathrm{m}}\left(\mathrm{Rh}^{0}-\mathrm{O}_{\mathrm{s}}{ }^{2-}\right) d /\left(4 R_{\mathrm{at}}\right)
$$

From calculations which relate the average rhodium-rhodium coordination number to the diameter $d$ for half-spherical-shaped particles, ${ }^{18}$ a diameter of about $11 \AA$ is derived from the coordination number $N=6.3$. By using this value, $R_{\mathrm{at}}=1.34 \AA$, and 
$N_{\mathrm{m}}\left(\mathrm{Rh}^{0}-\mathrm{O}_{\mathrm{s}}{ }^{2-}\right)=1.2$, we obtain $N_{\mathrm{r}}\left(\mathrm{Rh}^{0}-\mathrm{O}_{\mathrm{s}}{ }^{2-}\right)=2.5$. Possible structures for the metal-support interface are discussed in ref 18 .

In summary, we have found experimental evidence for a coordination of interfacial rhodium atoms with oxygen ions of the support. The bond length is $2.68 \AA$ with an estimated average coordination number of 2.5 atoms. Short oxide-like coordination distances have not been detected in fully reduced rhodium catalysts. The metal-support interaction is possibly through an ioninduced dipole interaction due to the registry of the metal particle with the support. The results presented in this work show that metal to support-oxygen bonds in supported metal catalysts can be detected when both the dispersion of the metal particles and the signal-to-noise ratio of the EXAFS data are high enough.
Acknowledgment. This work was done at SSRL (Stanford University), which is supported by the Department of Energy, The National Science Foundation, and the National Institutes of Health. We gratefully acknowledge the assistance of the SSRL staff and the assistance of Mr. E. F. Gleason and Dr. J. B. Michel in the preparation and characterization of the catalyst. This study was supported by the Netherlands Foundation for Chemical Research (SON) with financial aid from the Netherlands Organization for the Advancement of Pure Research (ZWO). D.C.K. and R.P. thank ZWO for supplying a travel grant (R71-34) and NATO for a research grant (1972), respectively.

Registry No. $\mathrm{Rh}, 7440-16-6 ; \mathrm{O}_{2}, 7782-44-7 ; \mathrm{Al}_{2} \mathrm{O}_{3}, 1344-28-1$

\title{
Kinetic Analysis of the Anomalous Behavior in the Fluorescence Quenching of Phenanthryl Groups Covalently Linked to Polyelectrolytes
}

\author{
Yotaro Morishima,* Takaomi Kobayashi, and Shun-ichi Nozakura \\ Department of Macromolecular Science, Faculty of Science, Osaka University, Toyonaka, Osaka 560, Japan \\ (Received: February 26, 1985)
}

\begin{abstract}
The fluorescence quenching of amphiphilic polyanions containing phenanthryl chromophores (APh) by bis(2-hydroxyethyl) terephthalate (BHET) was investigated in aqueous solutions over a concentration range of the phenanthryl residue of $8 \times$ $10^{-5}-3 \times 10^{-3} \mathrm{M}$. The steady-state experimental data were analyzed in terms of a kinetic model based on a stepwise association for the incorporation of BHET, an amphiphilic quencher, into the hydrophobic microdomains of the amphiphilic polymer. The polyanion with a phenanthryl content of $41 \mathrm{~mol} \%(\mathrm{APh}-41)$ showed fluorescence quenching for which Stern-Volmer-type plots gave a downward curvature. The initial slope was extremely steep and was dependent on the residue concentration of the phenanthryl chromophore. The quenching process was reasonably approximated as entirely static in nature. The first-step association constant for the BHET incorporation was estimated to be $K_{1}=1.1 \times 10^{3} \mathrm{M}^{-1}$, which is in fair agreement with the binding constant of $K=1.2 \times 10^{3} \mathrm{M}^{-1}$ obtained by the equilibrium dialysis technique. The analysis also led to estimates of the average aggregation number of the phenanthryl chromophores as $n=2.6$ for APh-41, through which energy migration could take place. The rate constant for the intradomain fluorescence quenching was estimated by computer curve fitting to be $k_{\mathrm{q} .1}=5.5 \times 10^{7} \mathrm{~s}^{-1}$. Under conditions where the BHET concentration is high enough for all the microdomains to incorporate the quencher, the fluorescence decay curve showed apparently single exponential nature, yielding $k_{\mathrm{q}, 1}=4.8$ $\times 10^{7} \mathrm{~s}^{-1}$ which is comparable to the computed value. In contrast, the amphiphilic copolymer with a phenanthryl content of $2 \mathrm{~mol} \%$ showed entirely dynamic quenching because of the absence of hydrophobic association of the quencher with the polymer.
\end{abstract}

\section{Introduction}

Polyelectrolytes chemically modified with polycyclic aromatic groups have been demonstrated to form microscopically phaseseparated structures in aqueous solutions because of their strong amphiphilic nature. ${ }^{1-4}$ Within a polymer chain of these polyelectrolytes the attractive hydrophobic interaction between the hydrophobic groups competes with the repulsive electrostatic interaction between the segmental electric charges as conceptually illustrated in Figure 1. The consequence of the competition critically determines the conformation of the macromolecular chains. In case the hydrophobic interaction prevails over the segmental Coulombic repulsion, the hydrophobic groups would end up forming hydrophobic microdomains. In this situation the charged segments would surround the periphery of the microdomains, thus the amphiphilic polyelectrolytes may provide a

(1) Y. Morishima, Y. Itoh, and S. Nozakura, Makromol. Chem., 182, $3135(1981)$

(2) Y. Itoh, Y. Morishima, and S. Nozakura, J. Polym. Sci., Polym. Chem. Ed., 20, 467 (1982).

(3) Y. Morishima, Y. Itoh, T. Hashimoto, and S. Nozakura, J. Polym. Sci., Polym. Chem. Ed., 20, 2007 (1982).

(4) Y. Morishima, T. Tanaka, Y. Itoh, and S. Nozakura, Polym. J., 14. $861(1982)$ "unimolecular" micelle. 5 This is actually the case for polyelectrolytes with a higher content of aromatic segments as will be discussed later. On the other hand, if the content of the hydrophobic segments is not high enough, the segmental Coulombic repulsion allows the polymer chain to expand, as usually occurs in the common polyelectrolytes. In the expanded conformation a hydrophobic group would be isolated from another along an electrolyte main chain and completely exposed to an aqueous environment. The photochemical behavior of the polycyclic aromatic groups is considerably dependent on whether the polymer conformation is expanded or miceller like. In a recent article concerning the photophysics of poly(methacrylic acid) containing pendant 9,10-diphenylanthracene, the emission properties and quenching rate constants of the photoactive group were shown to be strongly affected by the conformation of the polymer. ${ }^{7} \mathrm{We}$ have reported that the fluorescence quenching of the photoexcited phenanthryl groups in amphiphilic random copolymers of 9-

(5) Y. Itoh, Y. Morishima, and S. Nozakura, Photochem. Photobiol., 39, 603 (1984).

(6) Y. Morishima, Y. Itoh, S. Nozakura, T. Ohno, and S. Kato, Macromolecules, 17, 2264 (1984).

(7) J. A. Delaire, M. A. J. Rodgers, and S. E. Webber, J. Phys. Chem., 88, $6219(1984)$ 